\title{
Laparoscopic ligation of cisterna chyli for refractory chylothorax: A case series and review of the literature
}

\author{
Ilitch Diaz-Gutierrez, MD, Madhuri Vasudev Rao, MD, and Rafael Santiago Andrade, MD
}

\section{ABSTRACT}

Objectives: We describe an alternative surgical technique for the treatment of chylothorax in patients who have had failure of or are not candidates for transthoracic ligation or embolization by interventional radiology.

Methods: We describe our experience with laparoscopic ligation of the cisterna chyli in 3 such patients and compare our results with published literature. We used a 5-port approach as for foregut surgery. We retracted the liver, transected the gastrohepatic ligament, and retracted the stomach to the left. We exposed the right lateral aspect of the aorta at the level of the celiac trunk and clipped fatty tissue between the aorta and the right crus. We skeletonized the right crus and dissected from the right crus to the inferior vena cava. We then retracted the inferior vena cava laterally, exposed all soft tissue posteriorly, and identified the cisterna chyli posteromedially to the inferior vena cava. Finally, we ligated and clipped all fatty tissue between the right crus and the inferior vena cava.

Results: Success rate was $67 \% ; 1$ patient with idiopathic chylothorax did not have resolution and eventually died of multisystem organ failure. There were no procedure-related complications.

Conclusions: Laparoscopic ligation of cisterna chyli is an available therapeutic option for patients with chylothorax unresponsive to medical management, embolization, and transthoracic ligation of the thoracic duct. Our series is comparable with other reports of transabdominal approach to chylothorax. (J Thorac Cardiovasc Surg 2018;155:815-9)

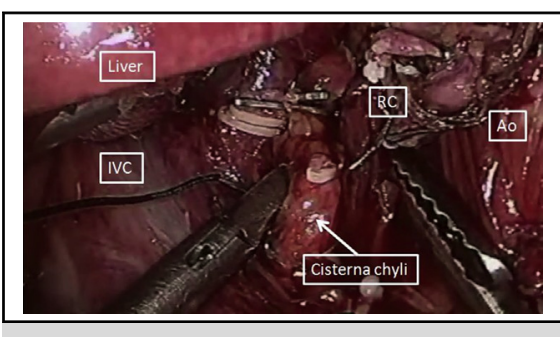

Cisterna chyli ligation.

\section{Central Message}

Laparoscopic cisterna chyli ligation is an available therapeutic option for refractory chylothorax unresponsive to medical management, embolization, and transthoracic ligation of the thoracic duct.

\section{Perspective}

We describe laparoscopic cisterna chyli ligation as an additional option to treat patients with chylothorax who have failed or are not candidates for transthoracic ligation or embolization of the thoracic duct. Laparoscopic ligation appears to be suitable for this challenging group of patients with multiple severe comorbid conditions.

See Editorial Commentary page 820 .

See Editorial page 814 .
Chylothorax is a morbid complication that occurs in $1.4 \%$ of patients after pulmonary resection ${ }^{1}$ and $3.8 \%$ of patients after esophagectomy. ${ }^{2}$ It is associated with higher

\footnotetext{
From the Division of Thoracic and Foregut Surgery, Department of Surgery, University of Minnesota, Minneapolis, Minn.

Read at the 97th Annual Meeting of The American Association for Thoracic Surgery, Boston, Massachusetts, April 29-May 3, 2017.

A waiver of institutional review board approval was granted for this retrospective study (STUDY00000980).

Received for publication May 8, 2017; revisions received Aug 14, 2017; accepted for publication Aug 31, 2017; available ahead of print Nov 9, 2017.

Address for reprints: Rafael Santiago Andrade, MD, Division of Thoracic and Foregut Surgery, Department of Surgery, University of Minnesota, 420 Delaware St SE, Mayo Mail Code 207, Minneapolis, MN 55455 (E-mail: andro0119@umn.edu). $0022-5223 / \$ 36.00$

Copyright (c) 2017 by The American Association for Thoracic Surgery https://doi.org/10.1016/j.jtcvs.2017.08.140
}

30-day major morbidity and mortality. ${ }^{2}$ Patients who have either had failure of or are not candidates for thoracic duct (TD) embolization or transthoracic ligation pose a particular challenge. We present a case series of laparoscopic cisterna chyli (CC) ligations in 3 such patients (Table 1).

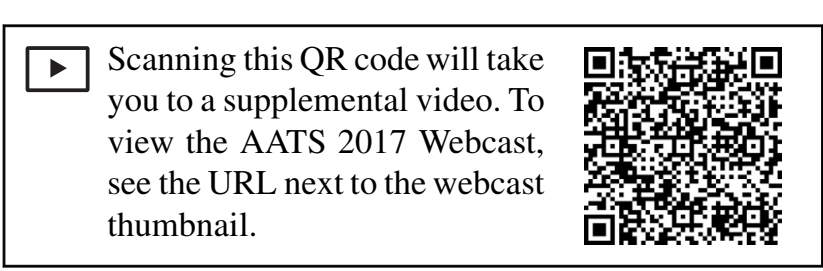




\section{Abbreviations and Acronyms \\ $\mathrm{TD}=$ thoracic duct \\ $\mathrm{CC}=$ cisterna chyli \\ $\mathrm{CT}=$ computed tomography \\ $\mathrm{IVC}=$ inferior vena cava}

\section{PATIENTS AND METHODS \\ Clinical Summary}

Case 1. An 82-year-old woman underwent spinal fusion for a T12 vertebral body fracture and had bilateral chylothoraxes develop. TD embolization was unsuccessful, and transthoracic ligation was deemed undesirable because of the suspected level of injury.

Case 2. A 42-year-old man was seen with idiopathic bilateral chylothoraxes. He underwent thoracoscopic TD ligation and talc pleurodesis, complicated by empyema and persistent chylothorax. Embolization by interventional radiology was thought to be fruitless because of the failure of the previous TD ligation.

Case 3. A 46-year-old woman with T4N0 Pancoast tumor underwent neoadjuvant chemoradiation and en bloc right upper lobectomy, chest wall resection, left innominate vein and superior vena cava resection and reconstruction, phrenic nerve resection, and diaphragm plication. She had development of a peripherally inserted central catheter line-associated deep vein thrombosis, bilateral chylothoraxes, and respiratory failure (Figure 1). Embolization by interventional radiology was deemed low yield because of left subclavian vein deep vein thrombosis.

\section{Surgical Technique}

All patients were approached with the technique described here. A waiver of institutional review board approval was granted for this retrospective study (STUDY00000980).

We used a 5-port approach as for foregut surgery (steep reverse Trendelenburg). We retracted the liver, transected the gastrohepatic ligament, and retracted the stomach to the left. We exposed the right lateral aspect of the aorta at the level of the celiac trunk and clipped fatty tissue between the aorta and the right crus. We skeletonized the right crus and dissected from the right crus to the inferior vena cava (IVC). Once we reached the IVC, we retracted it toward the right and exposed all soft tissue posterior to the IVC. We identified the CC posteromedially to the IVC in every case. Finally, we ligated and clipped all fatty tissue between the right crus and the IVC (Figure 2 and Video 1).

\section{RESULTS}

Chest tube output significantly decreased in all but the second case (Figure 3). There were no procedure-related

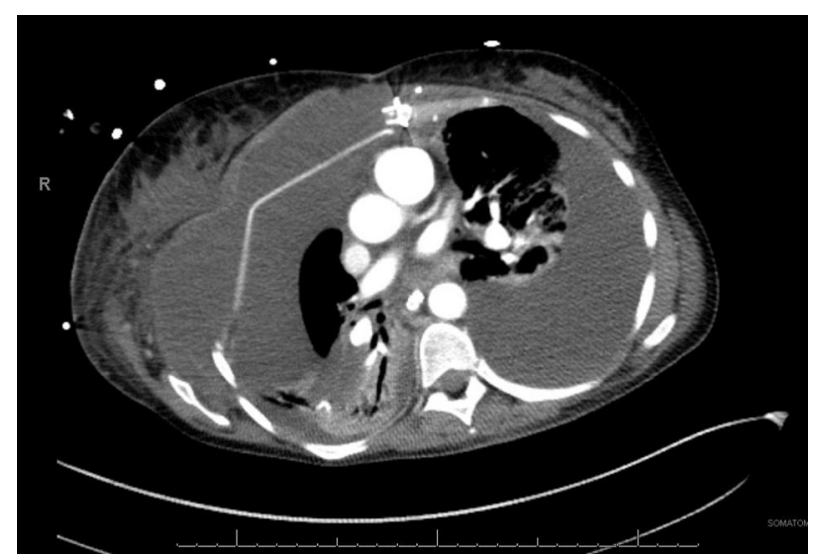

FIGURE 1. Chest computed tomographic scan showing large bilateral chylothoraxes in the setting of chest wall reconstruction with prosthetic nonabsorbable mesh.

complications. One patient had idiopathic chylothorax and eventually died from multisystem organ failure. Table 1 summarizes patient characteristics and outcomes.

\section{DISCUSSION}

We describe our experience with laparoscopic CC ligation in 3 difficult cases of patients who had either had failure of or were not candidates for TD embolization or transthoracic ligation.

A review of the literature (Table 2) reveals 3 small case series of ligation performed through a laparotomy ${ }^{3-5}$ and 4 case reports of laparoscopic ligation of $\mathrm{CC}$ or TD. ${ }^{6-9}$ The largest series of TD ligations through laparotomy, by Schumacher and colleagues, ${ }^{5}$ had a reported success rate of $75 \%$ to $95 \%$. The assumption that TD ligation at the level of the hiatus would lead to $100 \%$ success is improbable, because the anatomy of the lymphatic system is variable at this level. ${ }^{10}$ Interventional radiology embolization is therefore advantageous in delineating the anatomy before laparoscopic CC ligation.

Our technique is similar to the one used by Pandey and Lee $^{8}$ and Icaza and associates. ${ }^{7}$ We believe that our series suggests that the procedure is reproducible and appropriate in very ill patients who may not fare well with laparotomy. Two other case reports ${ }^{6,9}$ describe a laparoscopic transhiatal

TABLE 1. Patient characteristics and outcomes

\begin{tabular}{lclllccll}
\hline Case & Age $(\mathbf{y})$ & Sex & Diagnosis & Etiology & Chest tube (d) & LOS (d) & Outcome & In-hospital complications \\
\hline 1 & 82 & F & T12 fracture & Postoperative & 49 & 26 & D/C to rehab & Lower GI bleed \\
2 & 42 & M & Idiopathic & Unknown & 60 & 60 & Death & MOF, death \\
3 & 46 & F & Pancoast tumor & Postoperative & 7 & 14 & D/C to rehab & Respiratory failure \\
\hline
\end{tabular}

$L O S$, Length of stay; $F$, female; $D / C$, discharge; rehab, rehabilitation facility; $G I$, gastrointestinal; $M$, male; $M O F$, multiple organ failure. 


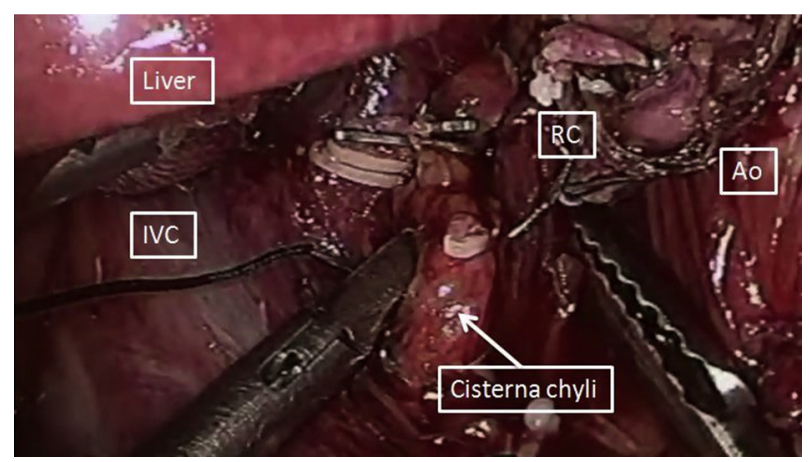

FIGURE 2. Ligation of cisterna chyli between aorta $(A o)$ and inferior vena cava $(I V C)$. $R C$, Right crus of the diaphragm.

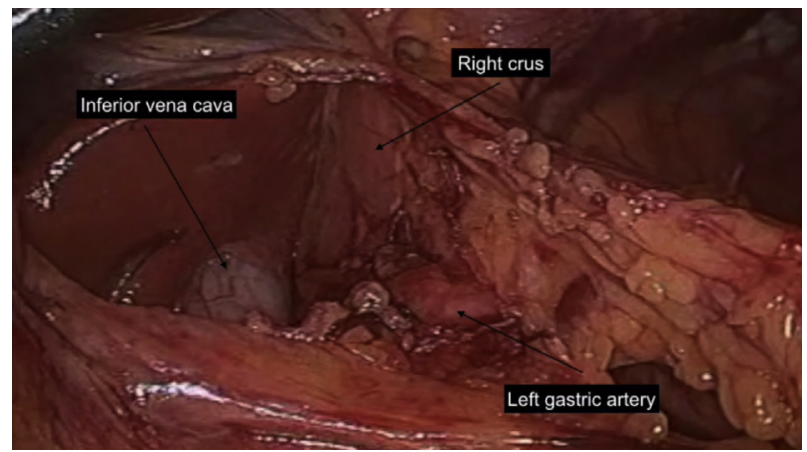

VIDEO 1. Laparoscopic ligation of cisterna chyli. Video available at: http://www.jtcvsonline.org/article/S0022-5223(17)32143-8/fulltext.

TD ligation; this represents a different principle and approach than CC ligation.

All these reports, including our series, have in common small numbers, heterogeneous patients, and good technical success rates (Table 2). Of our 3 patients, 2 had complete resolution of chylothorax; 1 patient, however, had persistent high chest tube output and eventually died. Although postoperative lymphoscintigraphy did not demonstrate a persistent chyle leak in that case (Figure 4), we concluded that we had not controlled the chylothorax. These findings suggest either that lymphoscintigraphy is not sensitive enough to detect certain chyle leaks, that the anatomy of the lymphatic system is variable and may defy clear delineation, or that our patient's underlying problem was more complex than an isolated spontaneous chylothorax.

Our experience has taught us that some patients are not suitable for lymphatic embolization if imaging studies are inconclusive, whereas others are not candidates for TD

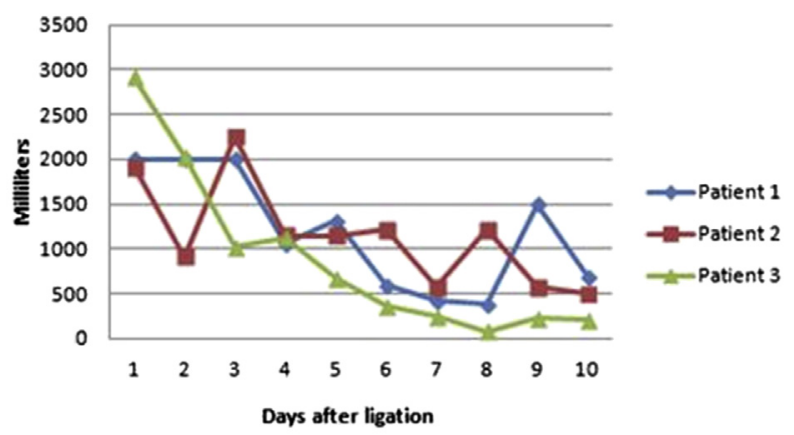

FIGURE 3. Combined chest tube output after cisterna chyli ligation. 
TABLE 2. Publications on trans-abdominal ligation of thoracic duct or cisterna chyli

\begin{tabular}{|c|c|c|c|c|c|c|c|}
\hline Reference & $\mathbf{N}$ & Etiology & Approach & Success & Complications & Mortality & Follow-up \\
\hline Mason $^{3}$ (1997) & 4 & Heterogeneous & Laparotomy & $100 \%$ & Sepsis & $25 \%$ & NA \\
\hline Mishra $^{4}(2013)$ & 6 & Postesophagectomy & Laparotomy & $100 \%$ & Candidemia & 0 & $9-30 \mathrm{mo}$ \\
\hline Schumacher $^{5}$ (2007) & 9 & Postesophagectomy & Laparotomy & $75 \%-95 \%$ & Pneumonia & $11 \%$ & NA \\
\hline Vasallo $^{6}$ (2002) & 1 & Post-right pleurectomy & $\begin{array}{l}\text { Laparoscopy } \\
\text { THTD ligation }\end{array}$ & $100 \%$ & - & 0 & NA \\
\hline Icaza $^{7}$ (2002) & 1 & $\begin{array}{l}\text { Post-right lower lobectomy, } \\
\text { failed ligation by } \\
\text { thoracotomy }\end{array}$ & Laparoscopy & $100 \%$ & Candidemia & 0 & NA \\
\hline Pandey $^{8}$ (2008) & 1 & $\begin{array}{l}\text { Posttraumatic, failed ligation } \\
\text { by thoracotomy }\end{array}$ & Laparoscopy & $100 \%$ & - & 0 & NA \\
\hline Tsubokawa $^{9}$ (2012) & 1 & Post--left EPP & $\begin{array}{l}\text { Laparoscopy } \\
\text { THTD ligation }\end{array}$ & $100 \%$ & - & 0 & NA \\
\hline Diaz-Gutierrez (2017)* & 3 & Heterogeneous & Laparoscopy & $67 \%$ & Sepsis, pneumonia & $33 \%$ & 8-34 mo \\
\hline
\end{tabular}

NA, Not available; THTD, transhiatal thoracic duct; $E P P$, extrapleural pneumonectomy. *Current report.

ligation if the chest cavity is scarred. Our current approach to these patients is first, lymphoscintigraphy with possible embolization; second, thoracoscopic TD ligation; and last, laparoscopic CC ligation.
The complex, rare, and heterogeneous nature of patients with refractory chylothorax necessitates a multidisciplinary approach. Prospective high-quality clinical studies seem unrealistic.

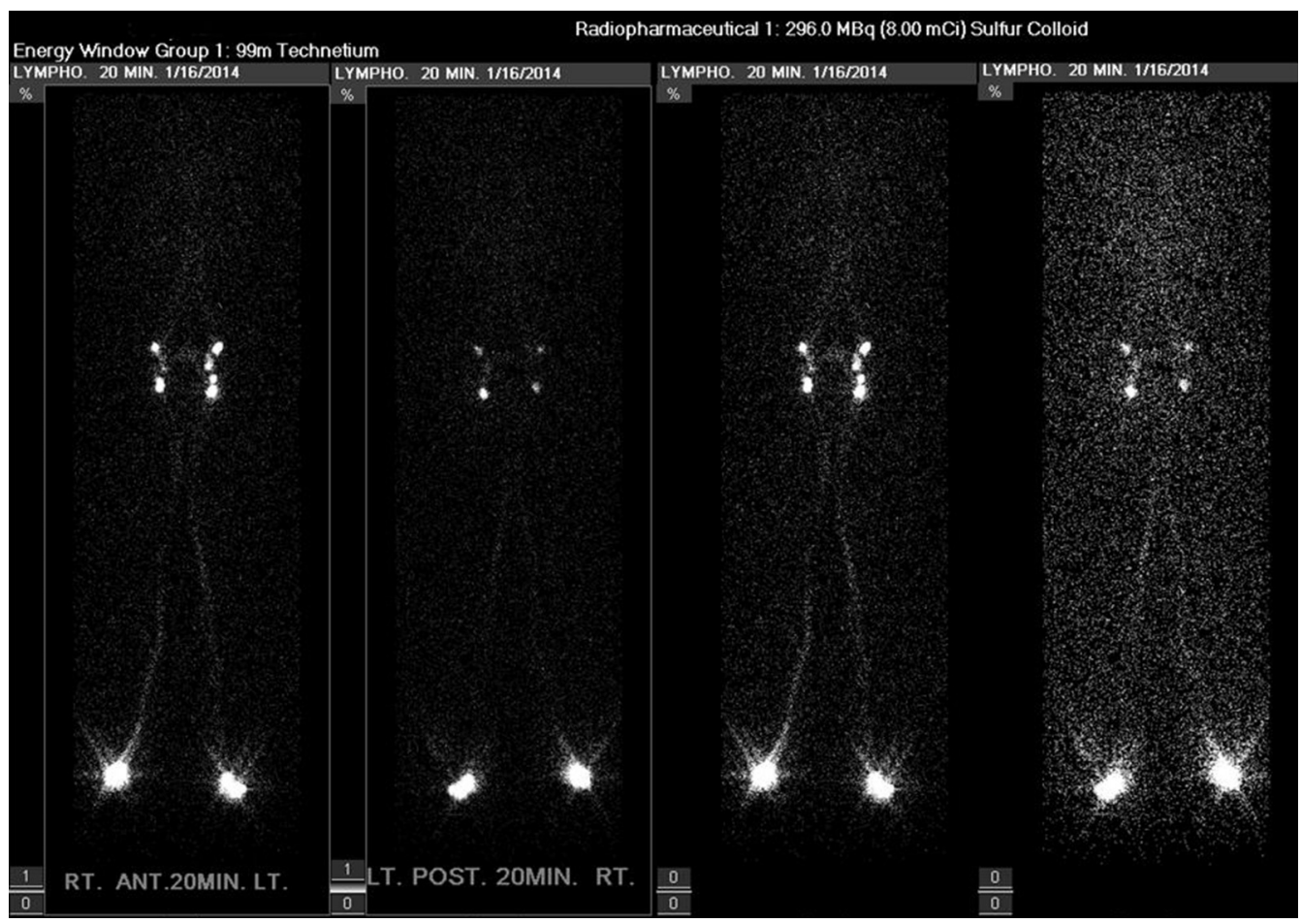

FIGURE 4. Lymphoscintigraphy demonstrating no radiotracer accumulation above the diaphragm. 


\section{CONCLUSIONS}

Laparoscopic ligation of $\mathrm{CC}$ is an available therapeutic option for patients with chylothorax unresponsive to medical management, embolization, and transthoracic ligation of the TD.

\section{Webcast}

You can watch a Webcast of this AATS meeting presentation by going to: https://aats.blob.core.windows.net/media/ 17AM/2017-05-02/RM302-304/05-02-17_Room302-304_ 0700_Diaz_Gutierrez.mp4.

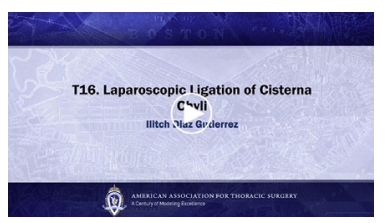

\section{Conflict of Interest Statement}

Authors have nothing to disclose with regard to commercial support.

\section{References}

1. Bryant AS, Minnich DJ, Wei B, Cerfolio RJ. The incidence and management of postoperative chylothorax after pulmonary resection and thoracic mediastinal lymph node dissection. Ann Thorac Surg. 2014;98:232-5; discussion 235-7.
2. Shah R, Luketich J, Schuchert M, Christie N, Pennathur A, Landreneau R, et al. Postesophagectomy chylothorax: Incidence, risk factors, and outcomes. Ann Thorac Surg. 2012;93:897-903; discussion 903-4.

3. Mason PF, Ragoowansi RH, Thorpe JA. Post-thoracotomy chylothorax - a cure in the abdomen? Eur J Cardiothorac Surg. 1997;11:567-70.

4. Mishra PK, Saluja SS, Ramaswamy D, Bains SS, Haque PD. Thoracic duct injury following esophagectomy in carcinoma of the esophagus: ligation by the abdominal approach. World J Surg. 2013;37:141-6.

5. Schumacher G, Weidemann H, Langrehr JM, Jonas S, Mittler J, Jacob D, et al. Transabdominal ligation of the thoracic duct as treatment of choice for postoperative chylothorax after esophagectomy. Dis Esophagus. 2007; 20:19-23.

6. Vassallo BC, Cavadas D, Beveraggi E, Sivori E. Treatment of postoperative chylothorax through laparoscopic thoracic duct ligation. Eur J Cardiothorac Surg. 2002:21:556-7.

7. Icaza OJ Jr, Andrews K, Kuhnke M. Laparoscopic ligation of the thoracic duct in management of chylothorax. J Laparoendosc Adv Surg Tech A 2002;12:129-33

8. Pandey R, Lee DF. Laparoscopic ligation of the thoracic duct for the treatment of traumatic chylothorax. J Laparoendosc Adv Surg Tech A. 2008;18: 614-5.

9. Tsubokawa N, Hamai Y, Hihara J, Emi M, Miyata Y, Okada M. Laparoscopic thoracic duct clipping for persistent chylothorax after extrapleural pneumonectomy. Ann Thorac Surg. 2012;93:e131-2.

10. Loukas M, Wartmann CT, Louis RG Jr, Tubbs RS, Salter EG, Gupta AA, et al. Cisterna chyli: a detailed anatomic investigation. Clin Anat. 2007;20 $683-8$.

Key Words: MeSH, chylothorax, thoracic duct, laparoscopy, ligation 